\title{
The Study of Magnetorheology of Iron Oxide Nanowires
}

\author{
S. P. Rwei, ${ }^{1}$ L. Y. Wang, ${ }^{2}$ and M. J. Chen ${ }^{1}$ \\ ${ }^{1}$ Institute of Organic and Polymeric Materials, National Taipei University of Technology, No. 1, Section 3, \\ Chung-Hsiao E. Road, Taipei 10648, Taiwan \\ ${ }^{2}$ Center of Condensed Matter Science, National Taiwan University, Taipei, Taiwan \\ Correspondence should be addressed to S. P. Rwei; f10714@ntut.edu.tw
}

Received 9 March 2013; Accepted 20 May 2013

Academic Editor: Subhankar Bedanta

Copyright (c) 2013 S. P. Rwei et al. This is an open access article distributed under the Creative Commons Attribution License, which permits unrestricted use, distribution, and reproduction in any medium, provided the original work is properly cited.

In this work, circular $\mathrm{Fe}_{3} \mathrm{O}_{4}$ particles with a diameter of $24 \mathrm{~nm}$ and quasicircular $\mathrm{Fe}_{3} \mathrm{O}_{4}$ particles with a diameter of $10 \mathrm{~nm}$ were synthesized using peptization and coprecipitation methods, respectively. The coprecipitated particles were further formed into $\mathrm{Fe}_{3} \mathrm{O}_{4}$ nanowires at high temperature and high pressure in a strongly alkaline environment. The optimal environment for forming nanowire was $15 \mathrm{~m}$ (molality) $\mathrm{NaOH}$ at $120^{\circ} \mathrm{C}$ for three days; the resulting proportional relationship between its width and its height, the aspect ratio, was 50.5/1. In the second part of this study, the nanoparticles and nanowire were dispersed in silicon oil and formed into magnetorheological (MR) fluids of different concentrations, before undergoing various MR tests-a shear test, a compression test, and a creep recovery test. The results revealed that the MR performance of nanowire fluid was better than that of circular particle fluid, in terms of yield stress ( $35 \mathrm{~Pa}$ versus $60 \mathrm{~Pa})$, compression displacement $(\Delta d)(0.19 \mathrm{~mm}$ versus $0.44 \mathrm{~mm})$, and creep recovery ratio ( $82 \%$ versus $48 \%$ ). The experimental results conclude that the nanowire network is more robust than the nanoparticle network. The test of the storage shelf time revealed that $12 \mathrm{wt} \%$ nanowire fluid retained more than $80 \%$ of its original yield stress after three months, indicating slight precipitation in the nanowire fluid. In summary, the nanowire MR fluid had a stronger MR effect than traditional MR fluid that was prepared with spherical MR particles.

\section{Introduction}

A magnetorheological (MR) suspension can be promptly transformed from a fluid-like structure to a solid-like structure with a viscoelastic to plastic yielding by subjecting it into a magnetic field [1-7]. Rabinow [8] discovered this phenomenon in 1948. Since then, various metal or ceramic powders with magnetic characteristics have been dispersed in nonmagnetic carrier liquids (such as oil or aqueous liquids) in the preparation of MR suspensions. Smart damper [9] is an important application of magnetorheological (MR) fluid. The releasing of its internal energy depends mainly on the viscosity of the dashpot. Therefore, a method for preparing MR fluid with a wide range of viscosities, ensuring a strong response of the yield stress or creep recovery from low to high magnetic strength, is crucial. Notably, $\mathrm{Fe}_{3} \mathrm{O}_{4}$, having a net ferromagnetic moment arising from the incomplete cancellation of spin materials of $\mathrm{Fe}^{2+}$ ions, can respond very sensitively to the magnetic fields. More importantly, the permanent magnetization of $\mathrm{Fe}_{3} \mathrm{O}_{4}$ nanoparticles is still weak enough that it cannot cause any interparticle agglomeration under zero magnetic field strength; $\mathrm{Fe}_{3} \mathrm{O}_{4}$ nanoparticle thus becomes a good candidate for the preparation of MR fluids. This work employs various chemical methods to synthesize $\mathrm{Fe}_{3} \mathrm{O}_{4}$ magnetic particles of various sizes and $\mathrm{Fe}_{3} \mathrm{O}_{4}$ magnetic nanowire and to form them into MR fluids, whose MR properties, including shear yield stress, compression resistance, creep recovery, and yield strength decay, are then observed. The goal is to find the formulation of MR fluids with optimal performance.

\section{Experimental}

2.1. Peptization Synthesis of Nanoparticle I [10-12]. Add iron chloride hexahydrate $(10.8 \mathrm{~g}, 80 \mathrm{mmol})$, sodium oleate $(36.5 \mathrm{~g}, 240 \mathrm{mmol})$ to a mixed solution of ethanol $(80 \mathrm{~mL})$, deionized water $(60 \mathrm{~mL})$, and hexane $(140 \mathrm{~mL})$. Stir the mixture well in a $500 \mathrm{~mL}$ three-neck flask that is mounted on a condensation system. Heat to $70^{\circ} \mathrm{C}$ and maintain this 
temperature for $4.5 \mathrm{~h}$; then purify three times using deionized water $(30 \mathrm{~mL})$ and finally store the iron-oleate complex product in hexane. Add iron-oleate complex $9 \mathrm{~g}$, oleic acid $1.7 \mathrm{~g}$ to $30 \mathrm{~g}$ tri-n-octylamine and stir well in a $500 \mathrm{~mL}$ threeneck flask. Heat at $3.3^{\circ} \mathrm{C} / \mathrm{min}$ to $366^{\circ} \mathrm{C}$ or $300^{\circ} \mathrm{C}$ and maintain this temperature for $30 \mathrm{~min}$. Wash the excessive oleic acid from the surface of $\mathrm{Fe}_{3} \mathrm{O}_{4}$ nanoparticles using ethanol or hexane, respectively.

2.2. Coprecipitation Synthesis of Nanoparticle II. To $6 \mathrm{~g}$ iron chloride tetrahydrate and $12 \mathrm{~g}$ iron chloride hexahydrate add $25 \mathrm{~mL}$ deionized water and mix to form an ionic solution. Add $50 \mathrm{~mL}$ ammonium hydroxide rapidly while agitating mechanically; keep stirring for $6 \mathrm{~min}$ and coprecipitate [1316] to obtain $\mathrm{Fe}_{3} \mathrm{O}_{4}$ nanoparticles. Use deionized water to wash off excessive ammonium hydroxide. Remove remaining deionized water in $\mathrm{Fe}_{3} \mathrm{O}_{4}$ nanoparticles by freeze-drying.

2.3. Hydrothermal Synthesis of Nanowire III. Put $0.5 \mathrm{~g} \mathrm{Fe}_{3} \mathrm{O}_{4}$ nanoparticles in a pressurized reaction flask and add sodium hydroxide solution to a concentration of $15 \mathrm{M}$. Place the flask in an oven and allow the hydrothermal reaction [1719] to proceed at $120^{\circ} \mathrm{C}$ (2 atm) for three days to yield $\mathrm{Fe}_{3} \mathrm{O}_{4}$ nanowires. Use deionized water to remove the excess sodium hydroxide solution. Remove the remaining deionized water from the $\mathrm{Fe}_{3} \mathrm{O}_{4}$ nanowires by freeze-drying.

2.4. Preparation of Magnetic Fluid. Add materials I, or II, or III to silicon oil with viscosities of $10 \mathrm{cp}$ and $100 \mathrm{cp}$ (polydimethylsiloxane PDMS). Stir well to obtain MR fluid. Pour the MR fluid into the groove on the lower plate of the rheometer (Anton Paar Physica MCR301 MRD). Then, lower the upper plate until the clearance is $0.1 \mathrm{~cm}$. The temperature of the rheometer is held constant, $25^{\circ} \mathrm{C}$. Apply various currents and measure the yield stress, the compression displacement, and the creep recovery rate of the specimen. The electronic micrographs were taken using transmission electron microscope at $300 \mathrm{kV}$ (TEM Hitachi: H-7100). The X-ray powder diffractometer (XRD PANalytical X'Pert PRO MPD), operated at $45 \mathrm{kV}$ and $20 \mathrm{~mA}$ under $\mathrm{CuK} \alpha$ radiation, was applied to analyze the crystal phase. The detector was scanned over a range of $4 \theta$ angles from $0^{\circ}$ to $70^{\circ}$ at a speed of $4^{\circ}$ per minute.

\section{Results and Discussion}

Figure 1 presents a TEM image of $\mathrm{Fe}_{3} \mathrm{O}_{4}$ nanoparticles that were synthesized by oleic acid peptization. The diameters of the particles are uniformly distributed with an average of $24 \mathrm{~nm}$. X-ray diffraction proves that the nanoparticles are pure $\mathrm{Fe}_{3} \mathrm{O}_{4}$ (Figure 2 lower curve). The peaks are consistent with the previous study [20]. Figure 3 presents a TEM image of $\mathrm{Fe}_{3} \mathrm{O}_{4}$ nanoparticles that were formed by coprecipitation. As is seen, the distribution of particle sizes is very broadmuch broader than achieved by peptization. The particles are not spherical but appear quasicircular or even polygonal. However, X-ray diffraction pattern (Figure 2-upper curve) proves that they are still pure $\mathrm{Fe}_{3} \mathrm{O}_{4}$ particles.

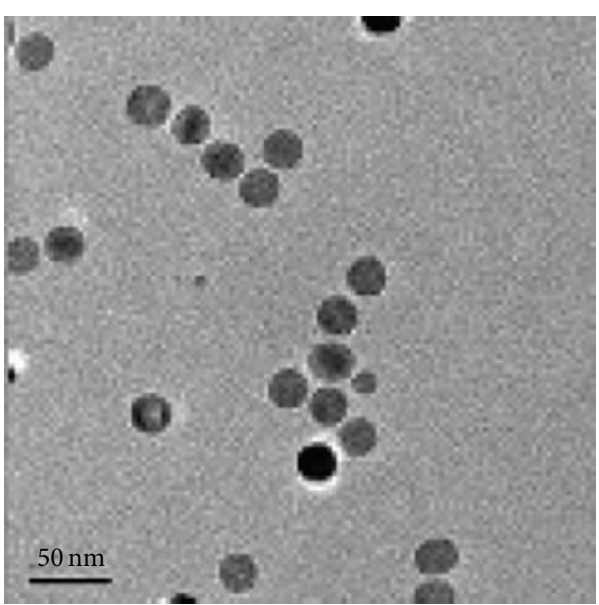

FIgURE 1: The TEM image of $\mathrm{Fe}_{3} \mathrm{O}_{4}$ nanoparticles synthesized by oleic acid peptization.

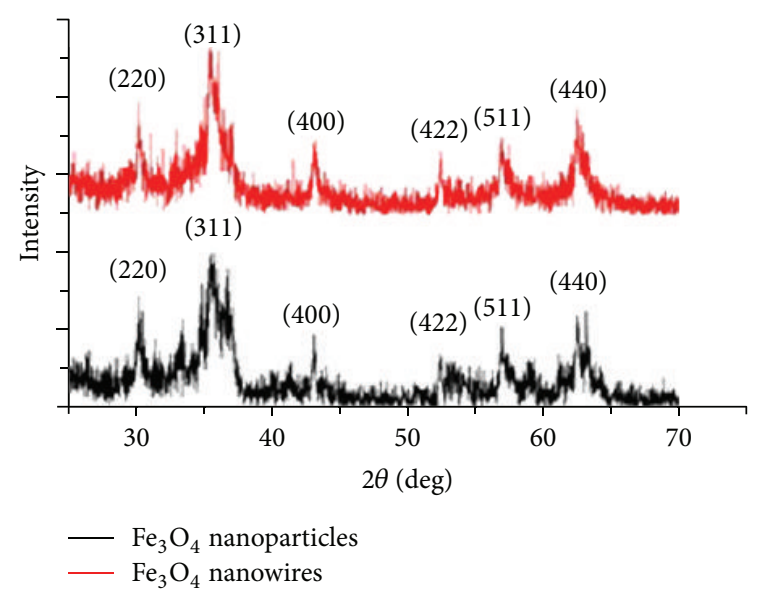

FIgURE 2: The X-ray diffraction spectrum of $\mathrm{Fe}_{3} \mathrm{O}_{4}$ nanoparticle and nanowire.

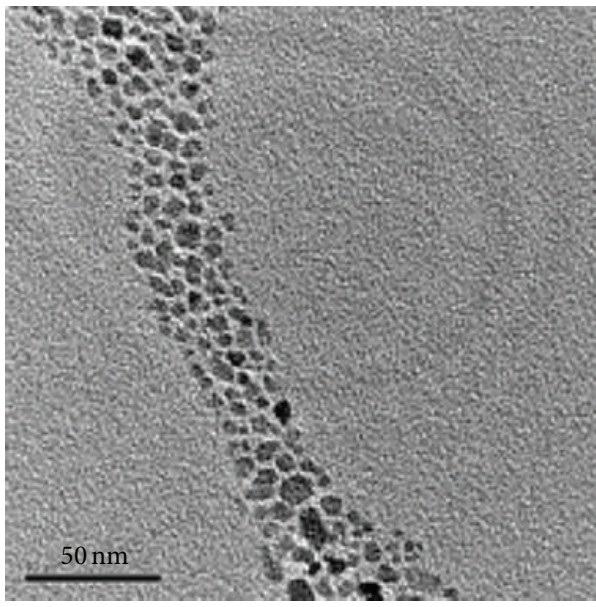

Figure 3: The TEM image of $\mathrm{Fe}_{3} \mathrm{O}_{4}$ nanoparticles formed by coprecipitation. 


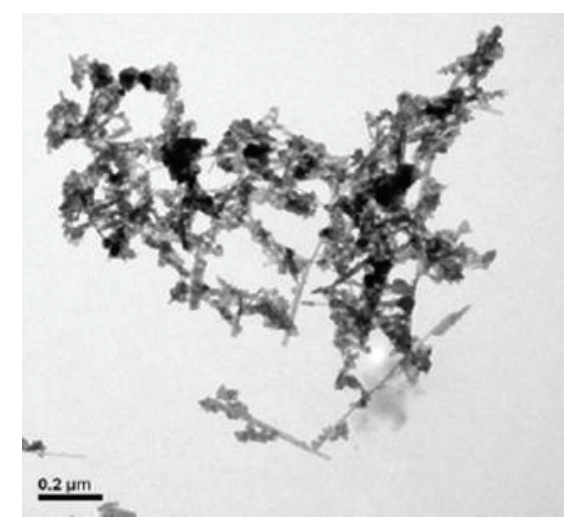

(a)

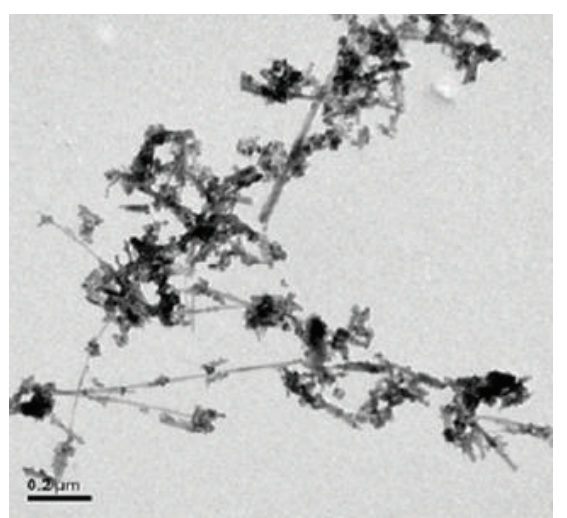

(b)

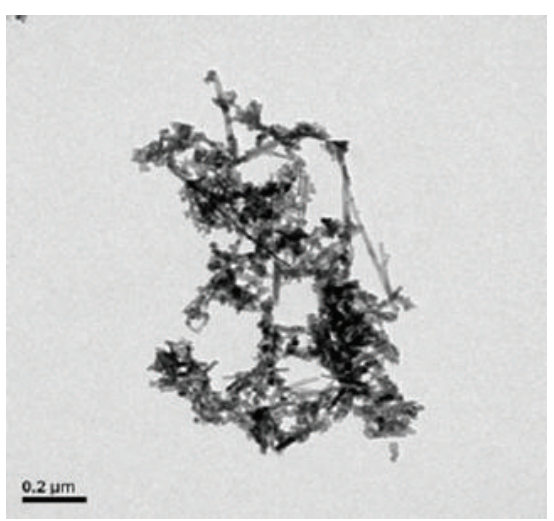

(c)

FIgURE 4: (a) (c) The TEM image of $\mathrm{Fe}_{3} \mathrm{O}_{4}$ nanowires formed at high temperature, $110^{\circ} \mathrm{C}$, and under various $\mathrm{NaOH}$ concentrations, (a) $5 \mathrm{~m}$, (b) $15 \mathrm{~m}$, and (c) $20 \mathrm{~m}$.

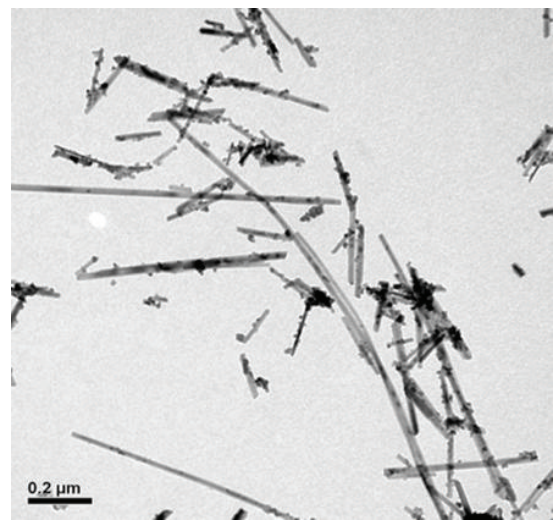

(a)

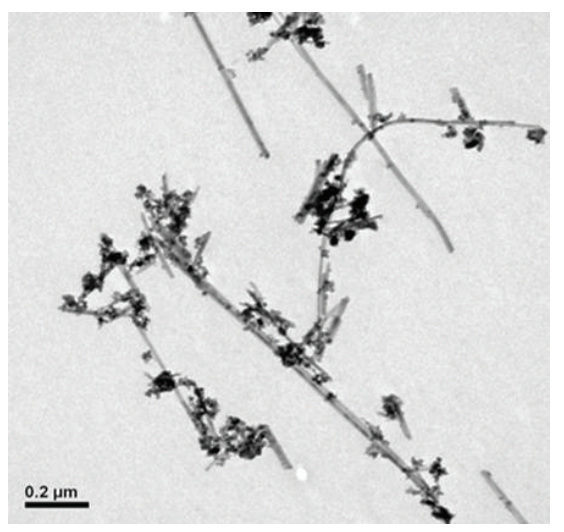

(c)

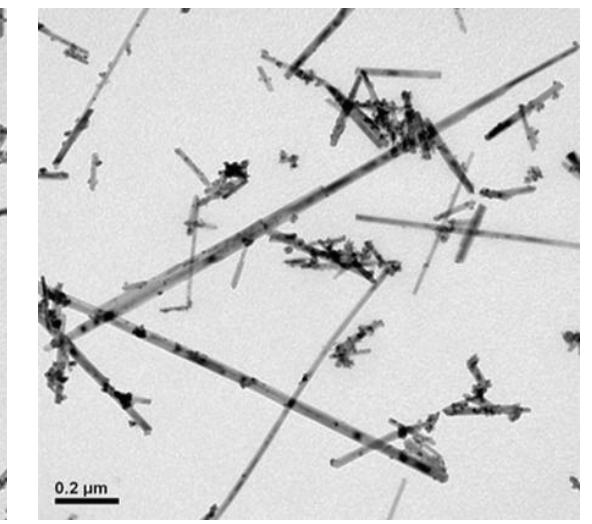

(b)

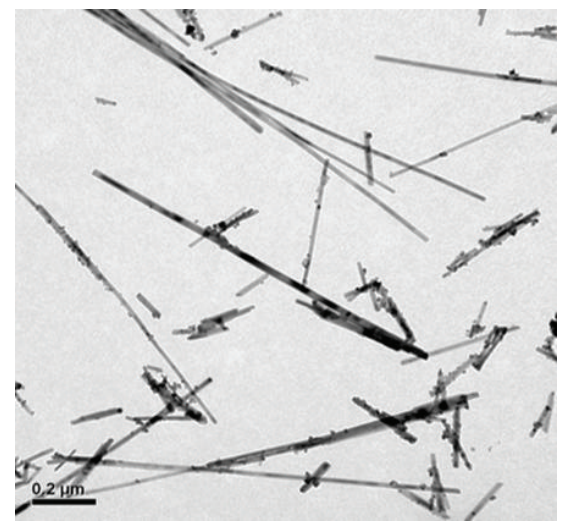

(d)

Figure 5: (a) (d) The TEM photographs of $\mathrm{Fe}_{3} \mathrm{O}_{4}$ nanowires synthesized under constant $\mathrm{NaOH}$ concentration, $15 \mathrm{~m}$, and at various temperatures or reaction durations, (a) $120^{\circ} \mathrm{C}, 3$ days, (b) $130^{\circ} \mathrm{C}, 3$ days, (c) $140^{\circ} \mathrm{C}, 3$ days, and (d) $120^{\circ} \mathrm{C}, 9$ days.

Figures 4(a)-4(c) present the influence of $\mathrm{NaOH}$ concentration on the lengths of $\mathrm{Fe}_{3} \mathrm{O}_{4}$ nanowires formed at high temperature $\left(110^{\circ} \mathrm{C}\right)$ and high pressure in a hydrothermal environment. As is seen, the nanowires were longest when the $\mathrm{NaOH}$ concentration was $15 \mathrm{~m}$. As the $\mathrm{NaOH}$ concentration was further increased, less deionized water can be vaporized, resulting in the pressure in the flask at high temperature being reduced. Consequently, the $\mathrm{Fe}_{3} \mathrm{O}_{4}$ nanoparticles are not driven to combine to form nanowire. The length of the rod shapes is therefore reduced. In short, the optimal environment in which to form nanowire is $15 \mathrm{~m} \mathrm{NaOH}$, which was utilized hereafter. 


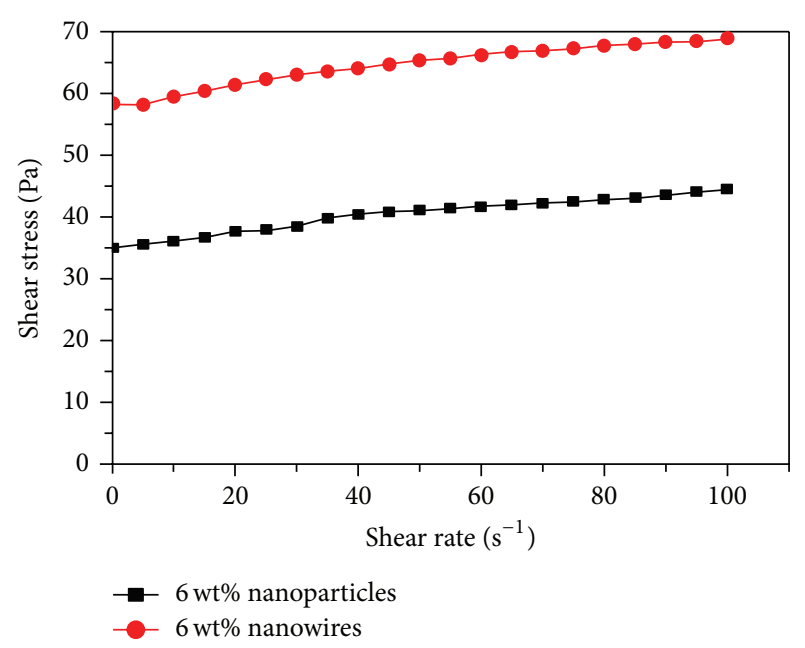

FIGURE 6: The plot of shear stress against shear rate for MR fluids containing $6 \mathrm{wt} \% \mathrm{Fe}_{3} \mathrm{O}_{4}$ nanoparticles and nanowires.

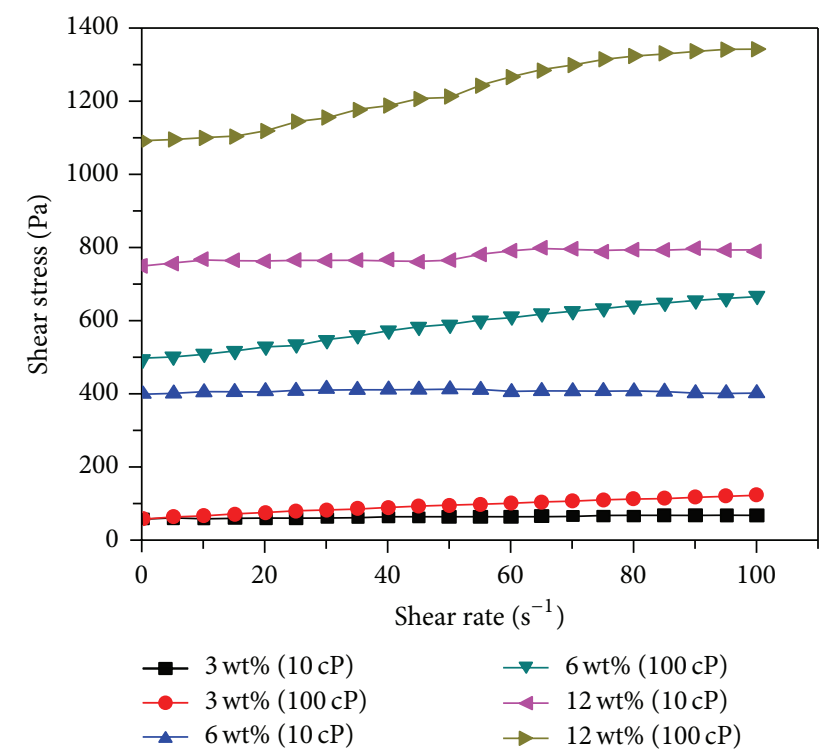

FIGURE 7: The plot of shear stress against shear rate for MR fluids containing nanowires at various solid loadings and dispersed at different viscosities of PDMS.

Figures 5(a)-5(d) present a TEM photograph of $\mathrm{Fe}_{3} \mathrm{O}_{4}$ nanowires that were synthesized at various temperatures or reaction durations. The conditions of Figure 5(a), including a temperature of $120^{\circ} \mathrm{C}$, in which the fewest particles were unreacted, were obviously optimal. Analysis of the image reveals that the aspect ratio of $50.5: 1$ obtained at $120^{\circ} \mathrm{C}$ is also the maximum value. The optimal conditions for forming $\mathrm{Fe}_{3} \mathrm{O}_{4}$ nanowire formation are thus determined to be $15 \mathrm{~m}$ $\mathrm{NaOH}, 120^{\circ} \mathrm{C}$, high pressure, and a strongly alkaline ambient.

As shown in Figure 6, the yield stress of $\mathrm{Fe}_{3} \mathrm{O}_{4}$ nanowire fluid, $60 \mathrm{~Pa}$, is nearly double that of $\mathrm{Fe}_{3} \mathrm{O}_{4}$ nanoparticle fluid, $35 \mathrm{~Pa}$, at the same concentration $(6 \mathrm{wt} \%)$. This result indicates that the asymmetry of nanowire can enhance the MR effect. Figure 7 plots the dependence of shear stress on

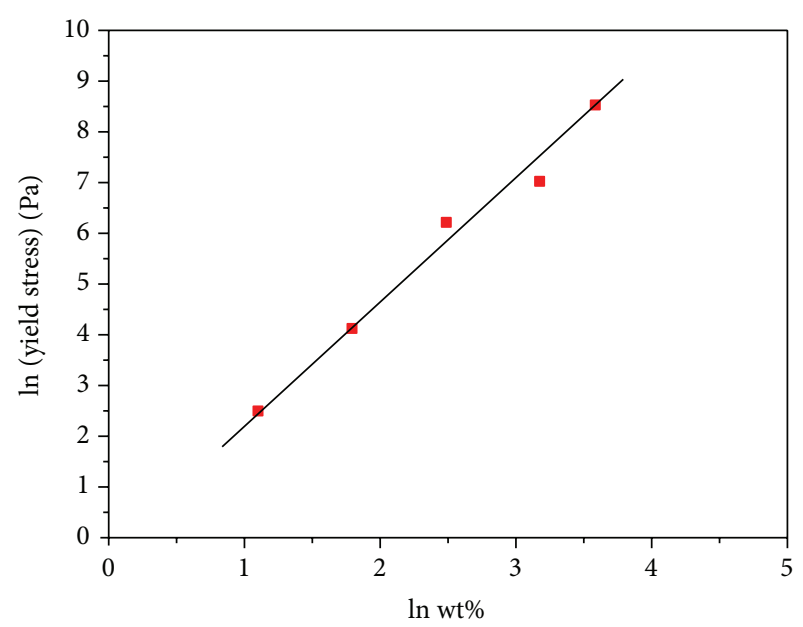

FIGURE 8: The yield stress is a function of solid loading of $\mathrm{Fe}_{3} \mathrm{O}_{4} \mathrm{MR}$ fluids.

shear rate for various concentrations of $\mathrm{Fe}_{3} \mathrm{O}_{4}$ nanowires that were suspended in silicon oil with various viscosities $(10 \mathrm{cp}$, $100 \mathrm{cp}$ ). The MR fluid exhibits typical Bingham character [21], with a yield stress threshold at which fluidity in a magnetic field is first exhibited. Figure 7 demonstrates that the yield stress increases with the nanowire concentration. Moreover, when the solid loading is $12 \mathrm{wt} \%$, the yield stress of the $100 \mathrm{cp}$ suspension is 1.5 times that of the $10 \mathrm{cp}$ suspension $(1100 \mathrm{~Pa}$ versus $720 \mathrm{~Pa}$ ). This result demonstrates that an increase of PDMS viscosity results in a higher yield stress at a given $\mathrm{Fe}_{3} \mathrm{O}_{4}$ loading. Figure 8 plots the yield stress against $\mathrm{Fe}_{3} \mathrm{O}_{4}$ solid concentrations when $0-36$ wt $\%$ of $\mathrm{Fe}_{3} \mathrm{O}_{4}$ nanowires are suspended in $100 \mathrm{cp}$ silicon oil. In the plot, as the solid loading increases, the yield stress increases as approximately a second-order polynomial (slope $=2.35$ ) function. Even though the increase of $\mathrm{Fe}_{3} \mathrm{O}_{4}$ loading positively affects the MR effect, the nanowire agglomeration that arises from high loading may occur seriously. This work demonstrates that the solid loading of $\mathrm{Fe}_{3} \mathrm{O}_{4}$ nanowires can be increased to $36 \mathrm{wt} \%$ without causing serious agglomeration. The authors' ultimate goal is to formulate a highly effective MR fluid at a sufficiently high concentration so that it can flow freely in a nonmagnetic field without solid-liquid separation but has a yield stress that can increase to $10^{4} \mathrm{~Pa}$ in a magnetic field.

Along with the shear test, the compression test can also be employed to characterize MR fluids. When a magnetic fluid is placed in a magnetic field, MR particles are temporarily in a network state, as shown in Figure 9(a). The purpose of shear test, as stated previously, is to determine the critical shear stress, also known as the yield stress that disrupts the network state. Similarly, the action of compression stress on the network can alter the network structure. Figure 9(b) demonstrates that under a given compression stress, a smaller change in volume, or a smaller $\Delta d$, corresponds to a greater magnetic attractive force among the magnetic particles within the network. When subjected to an external force, a more robust network is associated with a greater displacement resistance, and the displacement in 


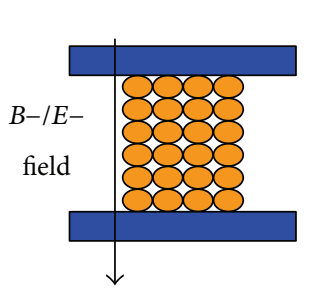

(a)
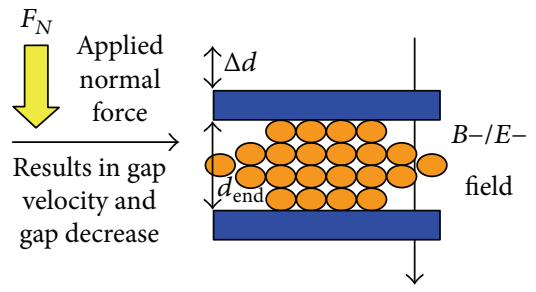

(b)
FIgURE 9: (a), (b) The illustration of structure change for an MR fluid under the compression test.

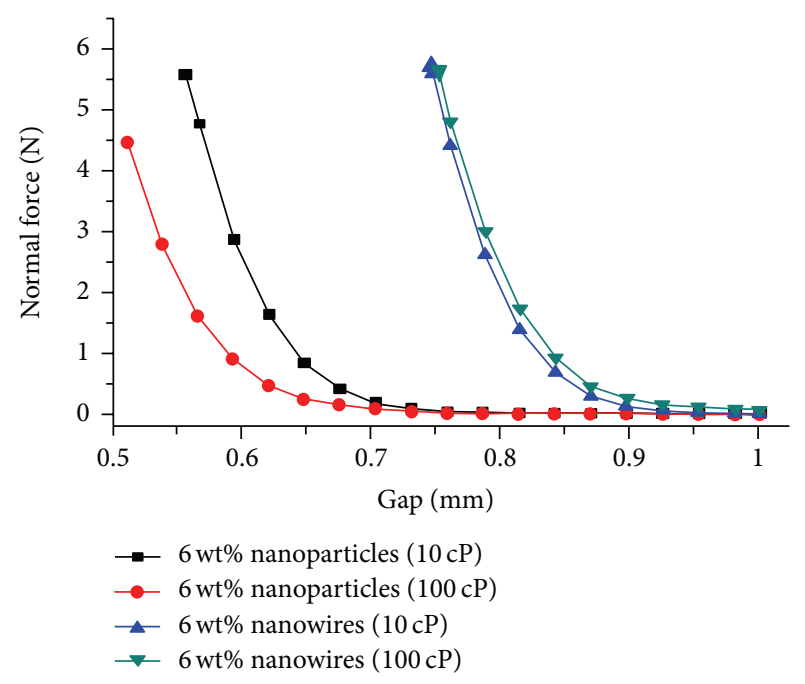

FIGURE 10: The plot of normal force versus gap distance for various MR fluids subjecting to the compression test.

the direction of the force is smaller. Figure 10 reveals that the compression displacements of the $\mathrm{Fe}_{3} \mathrm{O}_{4}$ nanoparticle are $0.39 \mathrm{~mm}$ and $0.44 \mathrm{~mm}$ in $10 \mathrm{cp}$ and $100 \mathrm{cp}$ silicon oil, respectively. In contrast, the compression displacements $(\Delta d)$ of the nanowires dispersed in $10 \mathrm{cp}$ and $100 \mathrm{cp}$ silicon oil are $0.19 \mathrm{~mm}$ and $0.07 \mathrm{~mm}$, respectively. The experimental result demonstrates that nanowire can exhibit favorable MR behavior. Additionally, the nanowire network has a higher compact density and toughness than the nanoparticle network. In fact, the particles are orientated and line up along the magnetic line of force with fewer joints. However, the line derived from the circular nanoparticles has more junctions than that derived from a nanowire. These junctions are the weakest points of the line. They usually collapse under a shear force or compression stress (Figures 11(a) and 11(b)). The resistance of the nanowire network to an external force is better because it has fewer junctions. The results also reveal that $10 \mathrm{cp}$ silicon oil is associated with a shorter compression displacement than $100 \mathrm{cp}$ silicon oil, perhaps because the former lubricates the joints less well than the latter. Better lubrication is generally associated with longer compression displacement.

The creep and recovery test $[22,23]$ focuses on investigating the recovery behavior of a magnetic network following

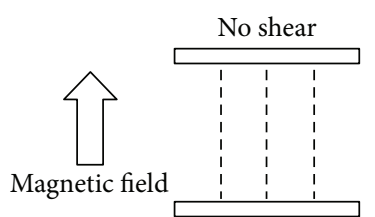

(a)

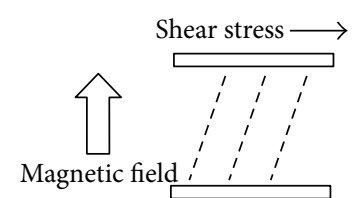

(b)
FIGURE 11: The illustration of $\mathrm{Fe}_{3} \mathrm{O}_{4}$ nanowires lining up along the magnetic line of force for the MR fluid (a) without shear and (b) under shear.

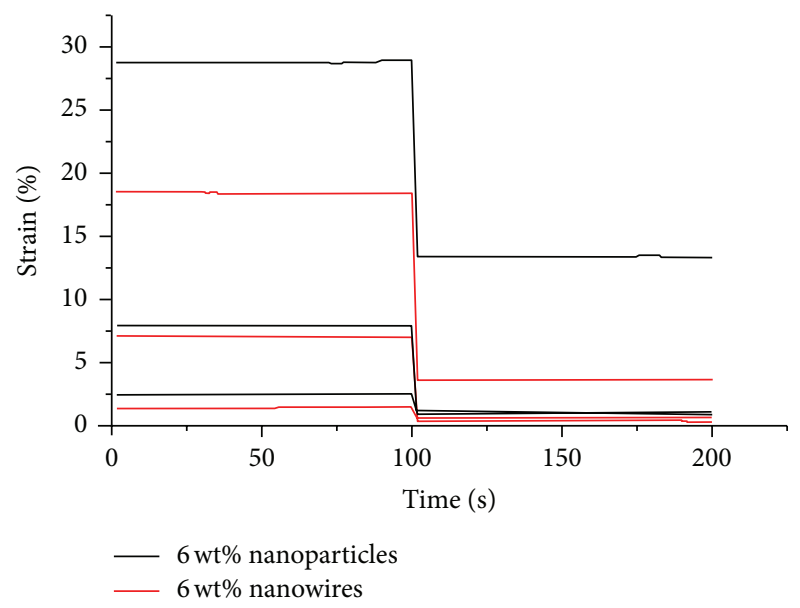

FIGURE 12: The plot of creep and recovery test for MR fluids containing 6 wt $\%$ of $\mathrm{Fe}_{3} \mathrm{O}_{4}$ nanoparticles and nanowires under various shear stresses $(10,20$, and $30 \mathrm{~Pa})$.

deformation by shearing, which has rarely been studied as part of MR investigations. In this work, the elasticity of the magnetic network structure is determined by applying a constant shear stress less than the yield stress to the MR fluid. The transient displacement of the MR structure reaches a constant, and then the stress is removed to observe the recovery of the MR fluid. A high recovery ratio demonstrates excellent elasticity of the magnetic network. It also indicates that the arrangement of magnetic particles inside the network is in a very stable state. Notably, the stress applied herein is less than the yield stress, and none of the magnetic fluids flows; rather, it exhibits various degrees of displacement. If obvious damage or permanent displacement occurs in the creep test, then the stress has permanently and detrimentally affected the relative positions of the network particles, such that the magnetic network structure fails to recover after shearing. This situation reveals that the solid character of the magnetic network is not strong. Figure 12 plots the result of the creep and recovery test for nanoparticles and nanowire. When the shear stress (10 Pa or $20 \mathrm{~Pa}$ ) is much less than the yield stresses of the MR fluids ( $35 \mathrm{~Pa}$ for nanoparticles and $60 \mathrm{~Pa}$ for nanowire), the recovery ratio of elasticity is nearly $100 \%$. However, at a shear stress of $30 \mathrm{~Pa}$, which is close to the yield stress of nanoparticles, the recovery ratio is only $48 \%$. In contrast, $30 \mathrm{~Pa}$ is far below the yield stress of the nanowire, for which the recovery ratio is $82 \%$. This result confirms 
that a nanowire network is more robust than a nanoparticle network. Additionally, Figure 12 shows that a network formed by the magnetic field suffers serious damage when the applied stress is only slightly less than the yield stress. Figure 13 plots the creep and recovery of MR fluids when the applied stress exceeds the yield stress. In the creep stage in Figure 13, the creep strain is not constant but increases with time. When the creep recovery stage is triggered 100 seconds later, the recovery is unobservable because the previous magnetic network structure had completely disintegrated. Even if the applied stress were terminated, a new network that is oriented with the magnetic field would gradually form, but it would have no relation to the previously damaged network in terms of structure or relative position of particles. Accordingly, recovery cannot occur when the applied stress exceeds the yield stress.

To determine whether the nanowire fluid meets the operating requirements, $12 \mathrm{wt} \%$ nanowire suspensions were stored for one, two, and three months, restirred, and then individually subjected to the MR shear test. Figure 14 shows that the yield stress decays from an initial value of $400 \mathrm{~Pa}$ at a rate from $20 \mathrm{~Pa}-30 \mathrm{~Pa}$ per month to $325 \mathrm{~Pa}$ after three months. This result shows that, because the size of the suspended nanowires is of the order of microns, their Brownian motion cannot overcome gravity, and precipitation eventually occurs. However, after restirring, this suspended matter is again dispersed, reducing the agglomeration. Figures 15(a) to 15(c) are TEM images of nanowire fluid with various storage periods. A comparison with Figure 5(b) reveals slight wire agglomeration, which, while not severe, should be reduced.

\section{Conclusions}

This systematic study of the preparation of magnetic particles preparation and their MR characterization supports the following conclusions.

(1) Circular $\mathrm{Fe}_{3} \mathrm{O}_{4}$ particles with a diameter of $24 \mathrm{~nm}$ and quasicircular $\mathrm{Fe}_{3} \mathrm{O}_{4}$ particles with a diameter of $10 \mathrm{~nm}$ were synthesized by peptization and coprecipitation. The peptized particles were formed into $\mathrm{Fe}_{3} \mathrm{O}_{4}$ nanowire at high temperature and high pressure in strongly alkaline environment. The optimal reaction conditions for forming nanowires are $15 \mathrm{~m} \mathrm{NaOH}$ at $120^{\circ} \mathrm{C}$ for three days. An aspect ratio as high as 50.5:1 can thus be achieved.

(2) The MR shear test revealed that the yield stress of $\mathrm{Fe}_{3} \mathrm{O}_{4}$ nanowire fluid is double that of the same concentration of $\mathrm{Fe}_{3} \mathrm{O}_{4}$ nanoparticle fluid. Furthermore, as the $\mathrm{Fe}_{3} \mathrm{O}_{4}$ particle concentration increases, the yield stress increases following a second-order polynomial (slope $=2.35)$ curve.

(3) The compression displacement $(\Delta d)$ of the $\mathrm{Fe}_{3} \mathrm{O}_{4}$ nanowire MR fluid is far less than that of the $\mathrm{Fe}_{3} \mathrm{O}_{4}$ nanoparticle MR fluid $(0.19 \mathrm{~mm}$ versus $0.44 \mathrm{~mm})$. The creep recovery capacity of $\mathrm{Fe}_{3} \mathrm{O}_{4}$ nanowire also exceeds that of $\mathrm{Fe}_{3} \mathrm{O}_{4}$ nanoparticle.

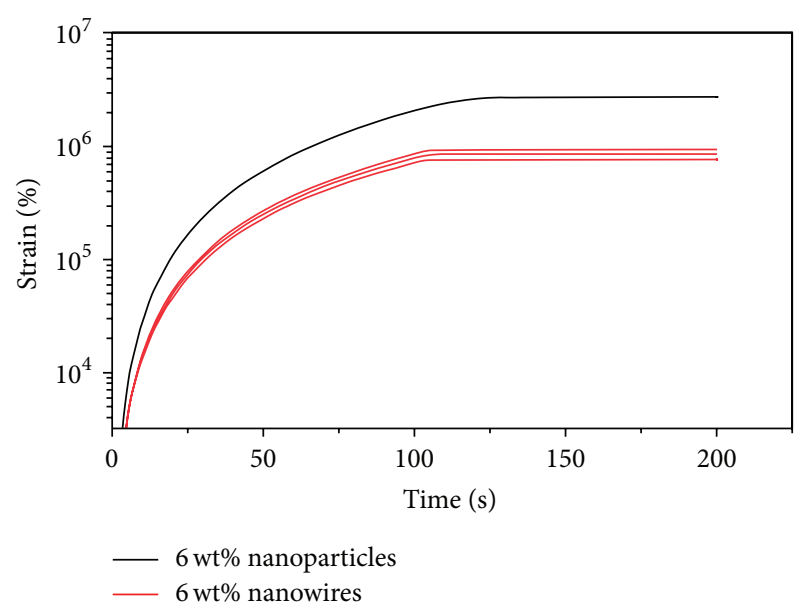

FIgURE 13: The plot of creep and recovery test for MR fluids containing $6 \mathrm{wt} \%$ of $\mathrm{Fe}_{3} \mathrm{O}_{4}$ nanoparticles and nanowires under shear stress of $70 \mathrm{~Pa}$, which is far above the yield stresses of both MR fluids. The experiment was repeated 3 times and a good reproducibility is shown.

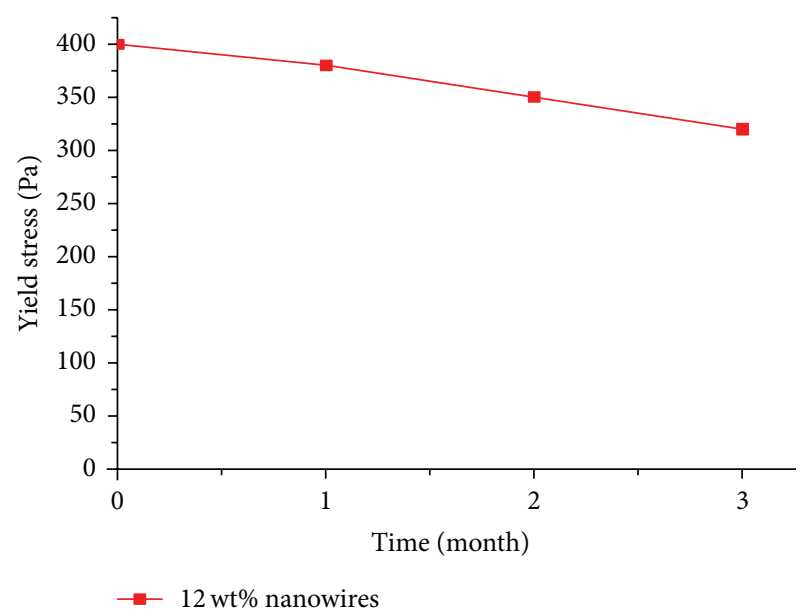

Figure 14: The plot of yield stress versus the shelf time for an MR fluid containing $12 \mathrm{wt} \%$ of $\mathrm{Fe}_{3} \mathrm{O}_{4}$ nanowires.

(4) The creep and recovery test showed that a network formed by the magnetic field had serious damage once the applied stress was close to the yield stress.

(5) In the storage test, $12 \mathrm{wt} \%$ nanowire fluid retained more than $80 \%$ of its original yield stress after three months.

In summary, nanowire magnetic particles can exhibit a better MR effect than traditional magnetic particles that were prepared with spherical MR particles.

\section{Conflict of Interests}

The MR fluid prepared according to the method mentioned herein is a novel method. Even though it still has long way to go for commercial application, its patents have been claimed 


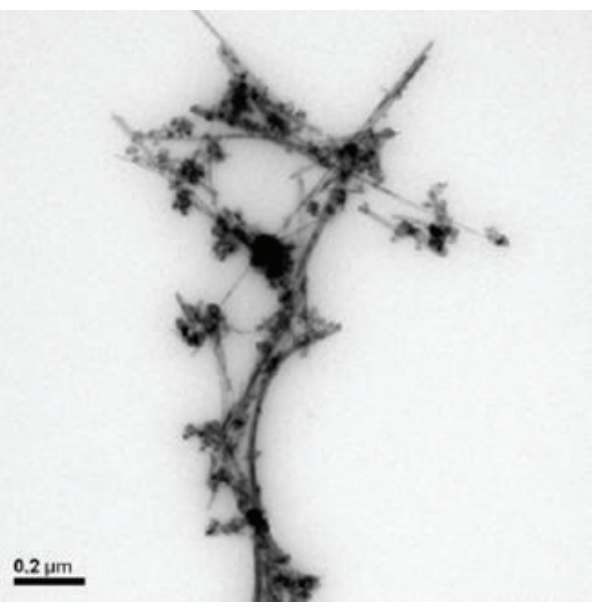

(a)

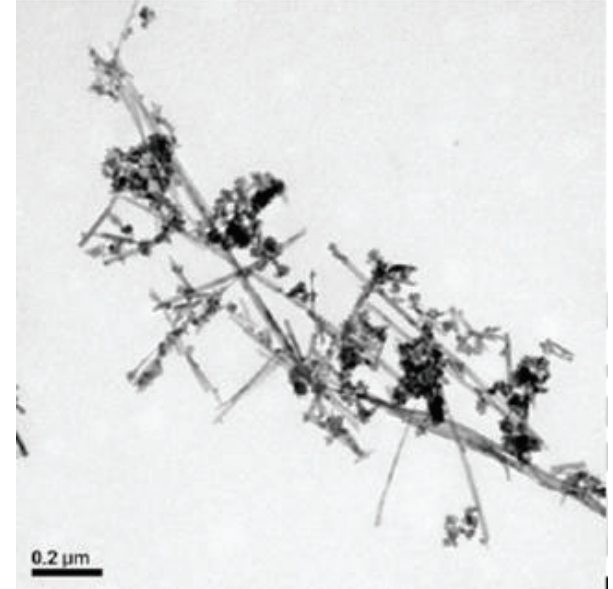

(b)

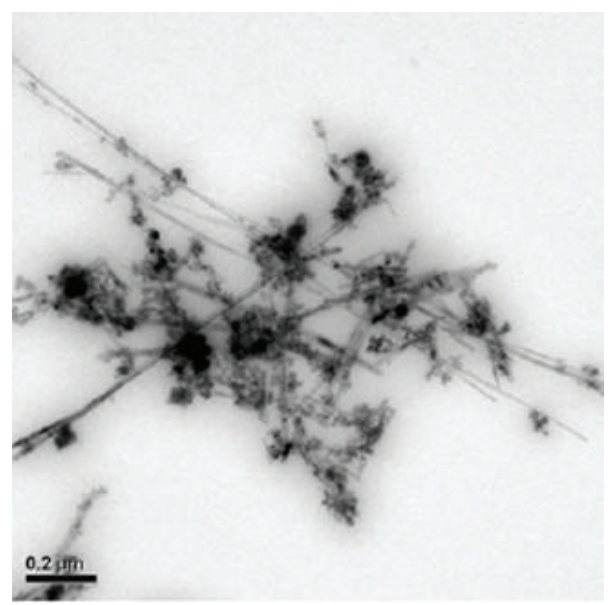

(c)

Figure 15: (a) (c) The TEM images of a MR fluid containing $12 \mathrm{wt} \% \mathrm{Fe}_{3} \mathrm{O}_{4}$ nanowires, which were stored at various periods of time: (a) 1 month, (b) 2 months, and (c) 3 months.

and filed by the authors and the financial founder: NSC of Taiwan. There is no conflict of interests for any commercial application at present time or in the future.

\section{Acknowledgment}

The authors would like to thank the National Science Council of Taiwan, for financially supporting this research under Contract no. NSC 98-2221-E-027-003-MY3.

\section{References}

[1] W. M. Winslow, "Induced fibration of suspensions," Journal of Applied Physics, vol. 20, no. 12, pp. 1137-1140, 1949.

[2] P. P. Phulé, "Magnetorheological (MR) fluids: principles and applications," Smart Materials Bulletin, vol. 2001, no. 2, pp. 710,2001

[3] G. Bossis, O. Volkova, S. Lacis, and A. Meunier, "Magnetorheology: fluids, structures and rheology," Stefan Odenbach, vol. 594, pp. 202-230, 2002.
[4] I. Bica and H. J. Choi, "Preparation and electro-thermoconductive characteristics of magnetorheological suspensions," International Journal of Modern Physics B, vol. 22, no. 29, pp. 50415064, 2008.

[5] J. L. Viota, J. de Vicente, J. D. G. Durán, and A. V. Delgado, "Stabilization of magnetorheological suspensions by polyacrylic acid polymers," Journal of Colloid and Interface Science, vol. 284, no. 2, pp. 527-541, 2005.

[6] A. J. F. Bombard, M. Knobel, and M. R. Alcântara, "Phosphate coating on the surface of carbonyl iron powder and its effect in magnetorheological suspensions," International Journal of Modern Physics B, vol. 21, no. 28-29, pp. 4858-4867, 2007.

[7] F. F. Fang and H. J. Choi, "Fabrication of multiwalled carbon nanotube-wrapped magnetic carbonyl iron microspheres and their magnetorheology," Colloid and Polymer Science, vol. 288, no. 1, pp. 79-84, 2010.

[8] J. Rabinow, "The magnetic fluid clutch," Transactions of the American Institute of Electrical Engineers, vol. 67, pp. 1308-1315, 1948.

[9] A. G. Olabi and A. Grunwald, "Design and application of magneto-rheological fluid," Materials and Design, vol. 28, no. 10, pp. 2658-2664, 2007. 
[10] X. Ren, "Large electric-field-induced strain in ferroelectric crystals by point-defect-mediated reversible domain switching," Nature Materials, vol. 3, no. 2, pp. 91-94, 2004.

[11] S. Sun, H. Zeng, D. B. Robinson et al., "Monodisperse $\mathrm{MFe}_{2} \mathrm{O}_{4}$ $(\mathrm{M}=\mathrm{Fe}, \mathrm{Co}, \mathrm{Mn})$ nanoparticles," Journal of the American Chemical Society, vol. 126, no. 1, pp. 273-279, 2004.

[12] T. Hyeon, "Chemical synthesis of magnetic nanoparticles," Chemical Communications, no. 8, pp. 927-934, 2003.

[13] R. Massart, "Preparation of aqueous magnetic liquids in alkaline and acidic media," IEEE Transactions on Magnetics, vol. 17, no. 2, pp. 1247-1248, 1981.

[14] J. Zhang, Q. Kong, J. Du, D. Ma, G. Xi, and Y. Qian, "Formation, characterization, and magnetic properties of $\mathrm{Fe}_{3} \mathrm{O}_{4}$ microoctahedrons," Journal of Crystal Growth, vol. 308, no. 1, pp. 159-165, 2007.

[15] J. Wang, K. Zhang, Z. Peng, and Q. Chen, "Magnetic properties improvement in $\mathrm{Fe}_{3} \mathrm{O}_{4}$ nanoparticles grown under magnetic fields," Journal of Crystal Growth, vol. 266, no. 4, pp. 500-504, 2004.

[16] S. Lian, E. Wang, L. Gao et al., "Growth of single-crystal magnetite nanowires from $\mathrm{Fe}_{3} \mathrm{O}_{4}$ nanoparticles in a surfactant-free hydrothermal process," Solid State Communications, vol. 132, no. 6, pp. 375-378, 2004.

[17] S. Lian, E. Wang, Z. Kang et al., "Synthesis of magnetite nanorods and porous hematite nanorods," Solid State Communications, vol. 129, no. 8, pp. 485-490, 2004.

[18] K. He, C.-Y. Xu, L. Zhen, and W.-Z. Shao, "Hydrothermal synthesis and characterization of single-crystalline $\mathrm{Fe}_{3} \mathrm{O}_{4}$ nanowires with high aspect ratio and uniformity," Materials Letters, vol. 61, no. 14-15, pp. 3159-3162, 2007.

[19] X. Lan, X. Cao, W. Qian, W. Gao, C. Zhao, and Y. Guo, "Long $\mathrm{Fe}_{3} \mathrm{O}_{4}$ nanowires decorated by CdTe quantum dots: synthesis and magnetic-optical properties," Journal of Solid State Chemistry, vol. 180, no. 8, pp. 2340-2345, 2007.

[20] G. Vaidyanathan, S. Sendhilnathan, and R. Arulmurugan, "Structural and magnetic properties of $\mathrm{Co}_{1-\mathrm{x}} \mathrm{Zn}_{\mathrm{x}} \mathrm{Fe}_{2} \mathrm{O}_{4}$ nanoparticles by co-precipitation method," Journal of Magnetism and Magnetic Materials, vol. 313, no. 2, pp. 293-299, 2007.

[21] J. M. G. Cowie and V. Arrighi, Polymers: Chemistry and Physics of Modern Materials, CRC Press, New York, NY, USA, 2007.

[22] I. G. Plashchina, N. V. Grinberg, E. E. Braudo, and V. B. Tolstoguzov, "Conformational transition and aggregation of $x$ carrageenan macromolecules in solution," Colloid and Polymer Science, vol. 258, no. 9, pp. 1038-1043, 1980.

[23] S.-P. Rwei and L. Wang, "Synthesis and electrical, rheological and thermal characterization of conductive polyurethane," Colloid and Polymer Science, vol. 285, no. 12, pp. 1313-1319, 2007. 

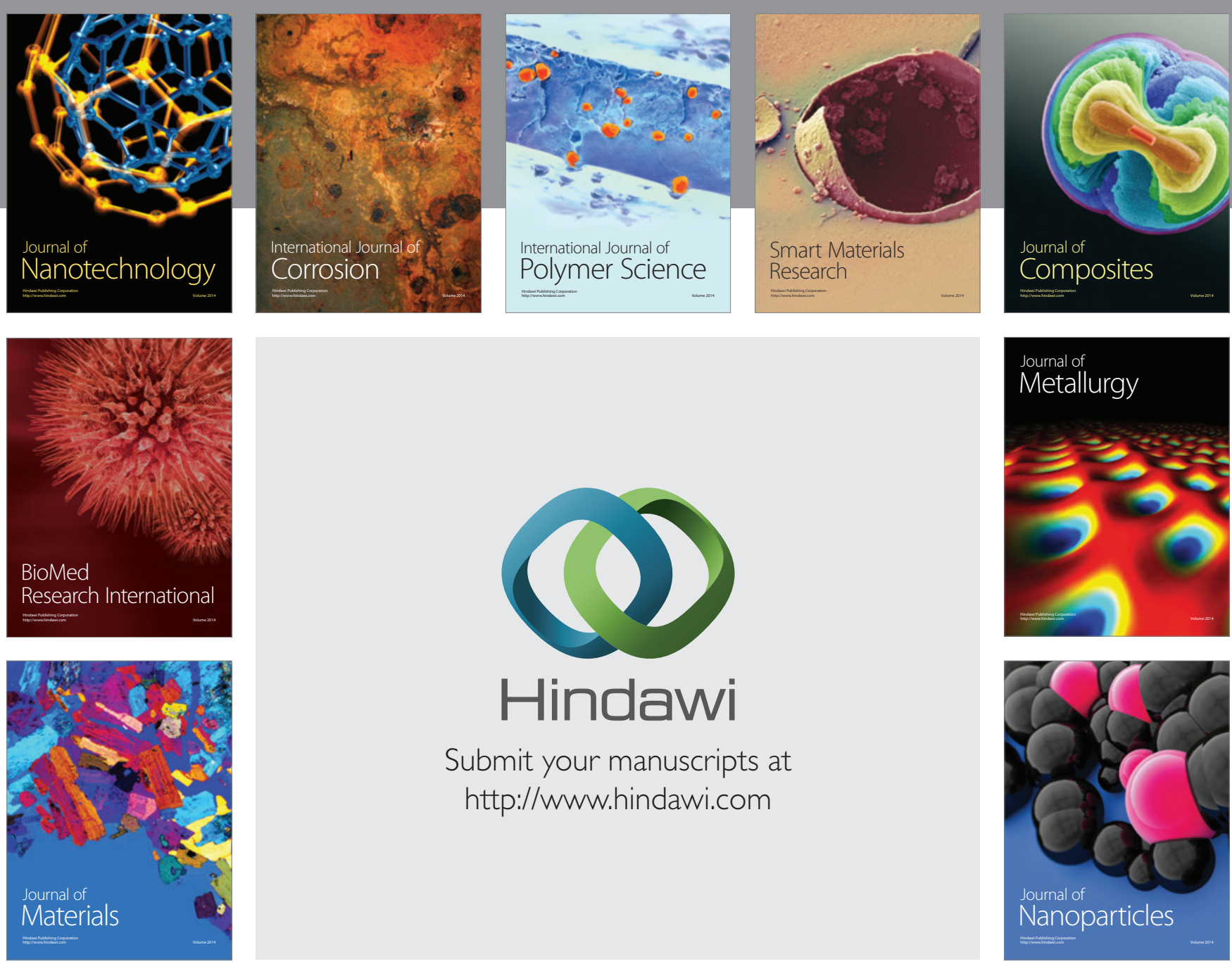

Submit your manuscripts at http://www.hindawi.com
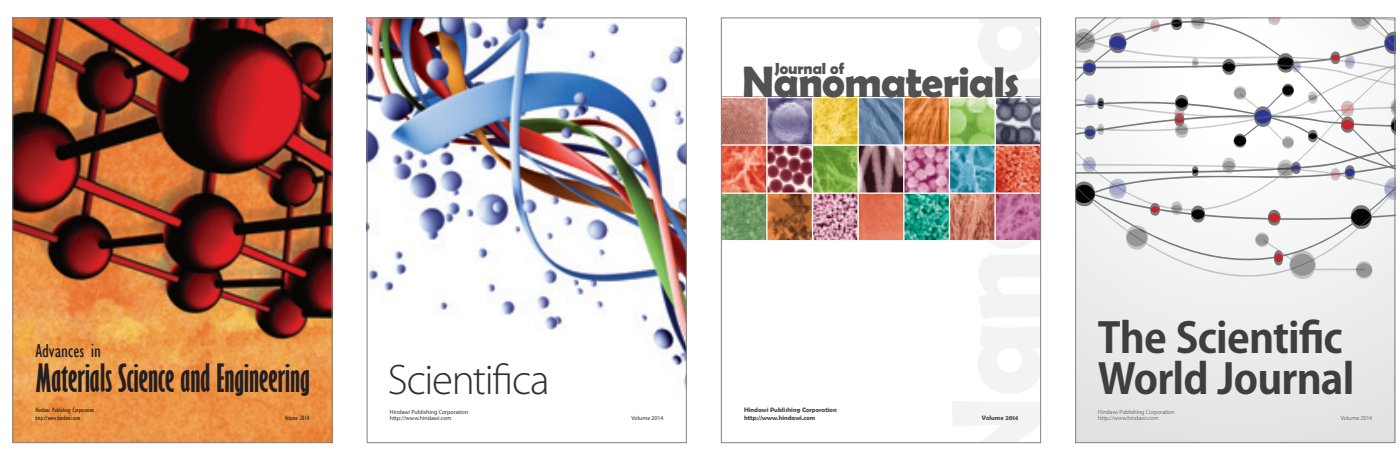

\section{The Scientific World Journal}
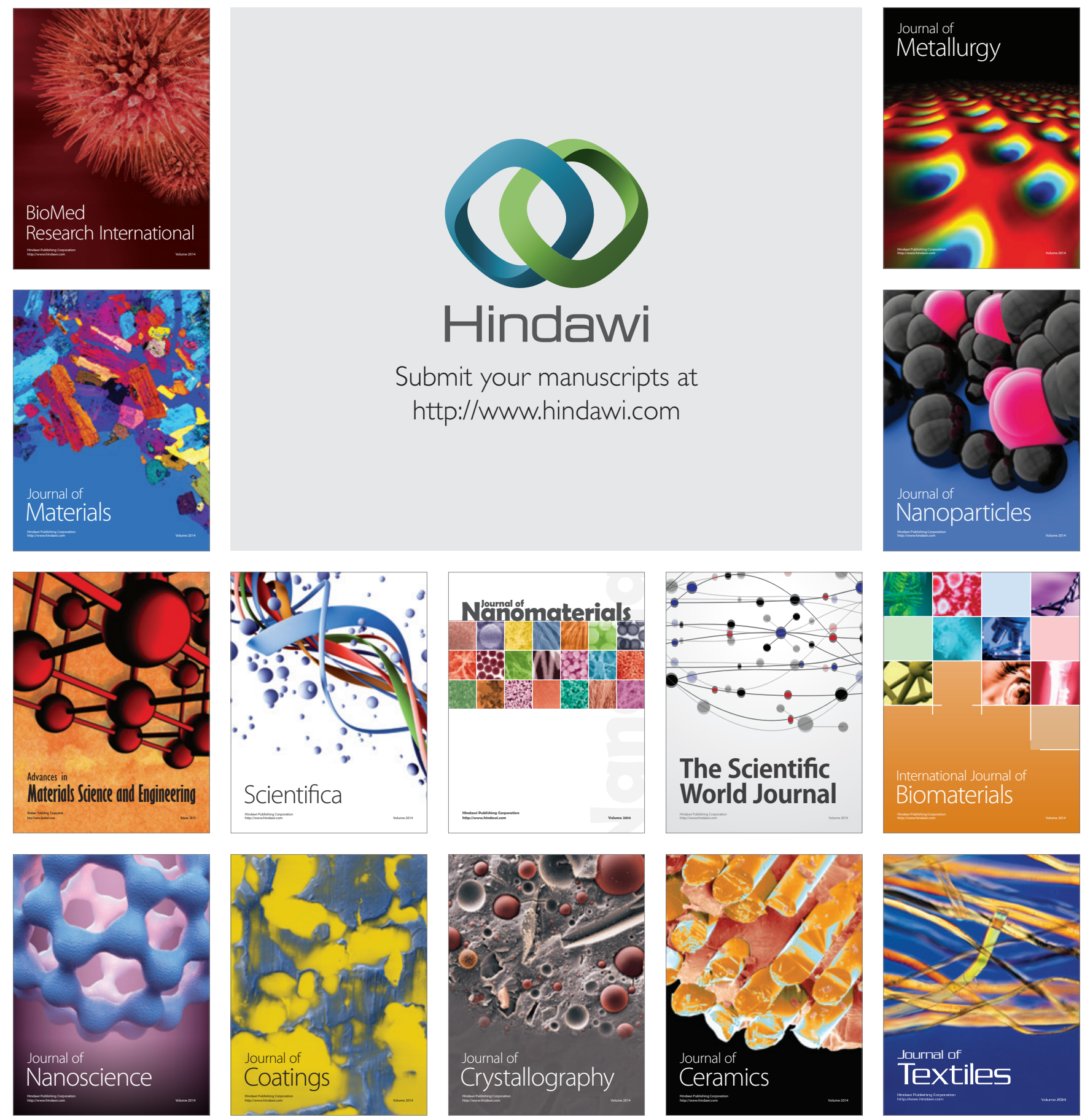